\title{
First-line management of menorrhagia: Findings from a survey of general practitioners in Forth Valley
}

\author{
Elaine Turner, MB ChB, General Practitioner, Killin Medical Practice, Perthshire, Scotland, UK \\ Paul Bowie BA, PgDip, Clinical Effectiveness Co-ordinator; Kathleen W McMullen, MB BS, MRCOG, MRCS, Consultant \\ Obstetrician and Gynaecologist, Stirling Royal Infirmary, Stirling, Scotland, UK
}

Catriona Kellock, BSc, RGN, Guidelines Facilitator, Forth Valley Health Board, Stirling, Scotland, UK

Correspondence: Dr Elaine Turner, Killin Medical Practice, Laggan Leigheas, Killin, Perthshire, FK21 8TQ, UK. Tel: 01567820213

(Accepted May 26 $\left.6^{\text {th }}, 2000\right)$

\begin{abstract}
Summary
This study was undertaken to determine local GPs' current management of menorrhagia, prior to the release of the Royal College of Obstetricians and Gynaecologists' (RCOG) guideline on the initial management of menorrhagia. A postal questionnaire was sent to 204 GPs in the Forth Valley area. An $84 \%(n=173)$ response rate was recorded. Responses were compared with RCOG guideline recommendations after its release. Fifty-two percent of respondents measured a full blood count and 56\% performed a pelvic examination. Two thirds of GPs chose the recommended treatments (mefenamic acid or tranexamic acid) as their first or second choice of treatment in women not requiring contraception. One third chose cyclical progestogens. Only 10\% of GPs selected an ineffective treatment (cyclical progestogens) as their first or second choice of treatment in women requiring contraception. This survey demonstrates that the majority of GPs are already prescribing the treatments recommended in the RCOG guidelines. There is a need for education amongst a minority to improve their practice. Half of the GPs reported compliance with the recommended investigations of full blood count and pelvic examination. The point at which these investigations are performed in the initial management of menorrhagia may need further discussion between primary and secondary care clinicians to clarify their purpose.
\end{abstract}

\section{Key words}

first-line management, menorrhagia, primary care

Key message point
- Survey of Forth Valley GPs' reported management of menorrhagia
reveals the majority practice in line with RCOG recommendations,
but there is still room for improvement.

\section{Introduction}

Menorrhagia, or heavy cyclical menstrual bleeding, is a common clinical condition, accounting for $5 \%$ of general practitioner (GP) consultations by women aged 30-49 years. ${ }^{1}$ Hospital referral after unsuccessful treatment constitutes a sizeable part of the gynaecology clinic workload (estimated at $12 \%$ ). ${ }^{2}$ The condition is the main indication for surgery in up to $50 \%$ of hysterectomies performed in the UK. ${ }^{3,4}$

The Royal College of Obstetricians and Gynaecologists (RCOG) has issued a clinical guideline which makes a series of recommendations based on the best current evidence. ${ }^{5}$ We performed this survey of current practice amongst local GPs prior to release of the RCOG guideline in order to help plan implementation of a locally agreed version of the guideline. The main guideline recommendations and the grades of evidence they are based on can be seen in Table 1 .

Table 1 Initial management of menorrhagia: RCOG guideline recommendations and levels of evidence.

1. An abdominal and pelvic examination should be performed in all women. 
Aim

To determine how Forth Valley GPs routinely investigate and treat women presenting with menorrhagia.

\section{Method}

A multidisciplinary working group was established in April 1998 to consider how best to develop a local guideline on the management of menorrhagia. The group agreed as a first step to collect baseline data on the first-line management of menorrhagia by local GPs to assess current practice.

A postal survey of the 204 GPs in the Forth Valley Health Board area was undertaken during September 1998. An individually signed covering letter explaining the nature of the study and what it hoped to achieve accompanied a selfcompleting questionnaire, together with a pre-paid envelope. Non-respondents were identified and a second mail-shot was arranged 2 weeks later.

\section{Results}

A total of 173 questionnaires were completed and returned by local GPs, a response rate of $85 \%$ (173/204). The main survey findings are outlined in Tables 2-4.

Table 2 Methods routinely used by GPs to diagnose menorrhagia.

\begin{tabular}{lcc}
\hline Method & Number (n) & Percent (\%) \\
\hline Patient history & 171 & 98.8 \\
Full blood count & 90 & 52.0 \\
Menstrual calendar & 62 & 35.8 \\
Other & 3 & 1.7 \\
\hline
\end{tabular}

\section{Discussion}

We were impressed by the high response rate achieved in this postal survey. The survey demonstrated that the majority of GPs chose effective treatments in the management of menorrhagia, when asked their prescribing habits in a postal questionnaire. However, this may differ from their actual practice in the consulting room.

The results indicate that the majority of GPs have appropriate knowledge, but a minority requires further education and more may need the support of a guideline to put their knowledge consistently into practice.

A slight majority of GP respondents performed a full blood count or pelvic examination as a routine investigation in the management of menorrhagia. A full blood count is recommended as the simplest objective test of excessive blood loss and a pelvic examination is recommended to exclude pelvic pathology. However, in younger women presenting with heavy cyclical menstrual bleeding, who appear reliable historians of their menstrual loss, it may not be necessary or appropriate to perform either of these investigations prior to first treatment, if it will not influence patient management. In a very young woman it may be more appropriate to consider a clotting disorder than to perform a pelvic examination. A full blood count is helpful where the diagnosis is in doubt or where anaemia is a clinical concern, but a normal result does not exclude the

Table 3 Number of GP respondents routinely performing a pelvic examination on a patient presenting with menorrhagia.

\begin{tabular}{lll}
\hline Respondents & Number (n) & Percent (\%) \\
\hline All GPs' & $97 / 173$ & 56.1 \\
*Male GPs' only & $46 / 108$ & 42.6 \\
*Female GPs' only & $46 / 60$ & 76.6
\end{tabular}

*Chi-square: $\mathrm{p}<0.01$ (gender not completed by 5 respondents)
Table 4 Range of drugs routinely prescribed by GPs as a $1^{\text {st }}$ or $2^{\text {nd }}$ choice in the treatment of menorrhagia prior to hospital referral.

\begin{tabular}{|c|c|c|c|c|}
\hline \multirow[t]{2}{*}{$\begin{array}{l}1^{\text {st }} \text { or } 2^{\text {nd }} \text { choice } \\
\text { drug prescribed }\end{array}$} & \multicolumn{2}{|c|}{$\begin{array}{l}\text { Women requiring } \\
\text { contraception }\end{array}$} & \multicolumn{2}{|c|}{$\begin{array}{l}\text { Women NOT } \\
\text { requiring contraception }\end{array}$} \\
\hline & (n) & $(\%)$ & (n) & $(\%)$ \\
\hline No treatment & 2 & 1.2 & 2 & 1.2 \\
\hline Danazol & - & - & 9 & 5.2 \\
\hline Mefenamic acid & 92 & 53.2 & 109 & 63.0 \\
\hline \multicolumn{5}{|l|}{ Cyclical progestogens } \\
\hline e.g. norethisterone & 13 & 7.5 & 66 & 38.2 \\
\hline Tranexamic acid & 66 & 38.2 & 111 & 64.2 \\
\hline Oral contraceptive pill & 139 & 80.3 & 16 & 9.2 \\
\hline Mirena coil & 16 & 9.2 & 3 & 1.7 \\
\hline Ethamsylate & 6 & 3.5 & 8 & 4.6 \\
\hline
\end{tabular}

diagnosis of menorrhagia. Given that these tests do not appear to be routinely performed at present by half of GPs, further discussion may be necessary between GPs and specialists on their appropriate use.

There was a significant difference in the proportions of male and female GPs who routinely performed a pelvic examination that requires further explanation. Female GPs may see the vast majority of women complaining of menorrhagia and have developed more expertise in this area of practice. Male GPs may refer women to their female partners for further management, including a pelvic examination. The need for a 'chaperone' to be present during the conduct of an intimate examination, particularly by male GPs, may be an issue and may require some reorganisation of services and resources. ${ }^{6}$

\section{Conclusions}

In summary, the study achieved its main objective by obtaining important knowledge of local GPs' practice in the management of menorrhagia. This will enable implementation of the guideline to be tailored to local need.

The main educational messages to promote are that low dose cyclical progestagens are ineffective and should not be prescribed, and that a wide range of effective medical treatments is available. This information also needs to be made available to women, and we have developed a patient information leaflet for this purpose. By offering women an effective first-line treatment it is likely that they will be satisfied with medical management. This might also reduce the hysterectomy rate in the longer term.

At present we are performing a further survey of patients' management when attending gynaecology outpatients to provide objective evidence of GPs' practice prior to referral. In future we plan to monitor GPs' prescribing patterns, hospital referral rates and surgical treatment rates to assess any changes in these areas.

\section{Acknowledgements}

We would like to thank the GPs of Forth Valley for participating in this study. Additional thanks are due to members of the Menorrhagia Working Group and to Dr Jim Robins at Inverclyde Royal Hospital.

\section{Statements on funding and competing interests \\ Funding: None \\ Competing interests. None}

References

Bradlow J, Coulter A, Brooks P. Patterns of referral Oxford Health Services Research Unit,

Coulter A, McPherson K, Vessey M. Do British women undergo too many or too few hysterectomies? Soc Sci Med 1998. 27: 987 994.

Coulter A, Klasen A, McPherson K. How many hysterectomies should purchas buy? Eur J Public Health 1995. 5: 123-129.

Coulter A, Klassen A, MacKenzie IZ, McPherson K. Diagnostic dilatation and curettage: is it used appropriately? Br Med J 1993; 306: 236-239.

Clinical Guideline: Initial management of menorrhagia. London: RCOG Press, October 1998

Report of the Working Party on Intimate Examinations. London: RCOG Press, 1997. 